\title{
Generation of Bio-Electricity From Whey
}

\author{
Abu Yousuf ${ }^{1 *}$, Pradip Saha ${ }^{1}$, Sreejon Das ${ }^{1}$, Salma Akhter Iqbal ${ }^{1}$, Ahmed Nazmus Sakib ${ }^{1}$, S.M. Anyet Ullah \\ Shohag ${ }^{1}$ \\ ${ }^{1}$ Department of Chemical Engineering and Polymer Science, \\ Shahjalal University of Science and Technology, Sylhet-3114, Bangladesh
}

\begin{abstract}
This study focused on the generation of electricity from whey in a bio-fuel cell (BFC). Whey or Milk Serum is the liquid remaining after milk has been curdled and strained. It is a by-product of the manufacture of cheese or casein in Foods and Sweets Company. It was selected as electrolyte in biofuel cell due to containing higher amount of branched-chain amino acids (BCAA's). The $\mathrm{pH}$ value of fresh whey was 3.1-3.8. Three categories of whey were used in the experiments included fresh whey, preserved by thermal treatment and preserved with $2 \%$ phenol by volume. It was observed that microorganism growth was zero in the sample with $2 \%$ phenol and growth rate was medium in the sample preserved by thermal treatment and that was higher in the fresh sample. In this biofuel cell, voltage was increased with the increase of surface area of electrodes. For a single compartment containing 8 unit cells, resultant voltage and current were $2.86 \mathrm{~V}$ and $450 \mu \mathrm{A}$ and four compartment 32 unit cells in series, the values were $10.90 \mathrm{~V}$ and $8.05 \mathrm{~mA}$ respectively. When anode area was increased to reduce polarization, power generation was initially high but the decreasing rate of power was also elevated. Finally, for commercial electrodes, maximum power and minimum internal resistance were recorded. The maximum Current, Voltage and Power for commercial electrodes in a single compartment containing 10 unit cells were $78 \mathrm{~mA}, 3.88 \mathrm{~V}$ and $0.30264 \mathrm{~W}$ respectively.
\end{abstract}

\section{INTRODUCTION}

The future of power production will certainly include fuel cell systems, which have recently attracted great attention by virtue of their inherently ultraclean, efficient, and reliable performance[1]. Fuel cells are fast replacing reciprocating engines and gas turbines as the most environmentally-friendly sources of on-site power. Fuel cells are really a family of technologies containing several primary types [2, 3] based on the type of electrolyte used. Among different types of fuel cell, many researchers have focused on experimental and theoretical studies of bio-fuel cells for its vantages [3-5]. BFCs convert chemical energy directly into electricity without the combustion process. Moreover, a high power density allows BFCs to be relatively compact source of electric power. Furthermore, BFCs are extremely quiet in operation.

Organic acid like amino acid is used as electrolyte in biofuel cell. Whey is one of the pronounced sources of amino acid. It is a dilute solution of protein, lactose, fat and ash. Protein consists of long chain amino acid. The weak organic acid of electrolyte dissociates in this aqueous solution, consequently $\mathrm{H}^{+}$ions are increased [6]. In the meantime, $\mathrm{Zn}$ plate dissolved in the organic electrolyte as $\mathrm{Zn}^{2+}$ ion sacrificing two electrons. Electrons pass through the external circuit and salt of $\mathrm{Zn}$ is produced. On the other hand $\mathrm{H}^{+}$ions are adsorbed on the surface of $\mathrm{Cu}$ plate and receiving electron, they evaluated as $\mathrm{H}_{2}$ gas.

$\mathrm{H}_{2} \mathrm{~N}-\mathrm{CHR}-\mathrm{COOH} \rightarrow \mathrm{H}_{2} \mathrm{~N}-\mathrm{CHR}_{-} \mathrm{COO}^{-}+\mathrm{H}^{+}$ $2\left(\mathrm{H}_{2} \mathrm{~N}-\mathrm{CHR}-\mathrm{COO}^{-}\right)+\mathrm{Zn}^{2+} \rightarrow\left(\mathrm{H}_{2} \mathrm{~N}-\mathrm{CHR}-\mathrm{COO}\right){ }_{2} \mathrm{Zn}$
At anode: $\mathrm{Zn}(\mathrm{s}) \rightarrow \mathrm{Zn}^{2+}$ (aq.) $+2 \mathrm{e}^{-}$

At cathode: $2 \mathrm{H}^{+}$(aq.) $+2 \mathrm{e}^{-} \rightarrow \mathrm{H}_{2}(\mathrm{~g})$

In this study, we tried to search a suitable biomass source that could be used as electrolyte, to develop their preservation technique, design and fabrication of biofuel cell, and study the feasibility of electricity generation from selected bio-sources.

\section{MATERIALS AND METHODS}

\subsection{Electrolyte selection}

Several biomass sources were studied as BioElectrolyte and selected on the basis of some properties like low $\mathrm{pH}$, high electric conductivity, economical and easily available. We studied with tomato juice, tamarind juice, and milk whey.

\subsection{Electrolyte processing \& preservation}

Two pretreatment processes were applied to preserve the fresh bio electrolyte (whey). The processes were as presented in Table- 1 .

Table-1: Preservation Technique of electrolyte

\begin{tabular}{lll}
\hline No. & Types of process & Procedure \\
\hline I & Preserving whey with & By adding 2\% \\
& antimicrobial reagent & phenol \\
II & Preserving whey with & Thermal treated at \\
& heat treatment & $70^{\circ} \mathrm{C}$ about 5-7 \\
& & minute (without \\
& & adding any \\
& & antimicrobial \\
& & reagent) \\
\hline
\end{tabular}




\subsection{Biofuel Cell design}

The basic parts of a biofuel cell were the cell box, electrodes, separator, plastic pipes, circulating pump, wood stand and connecting wire. The cells were designed and connected as Fig.1.

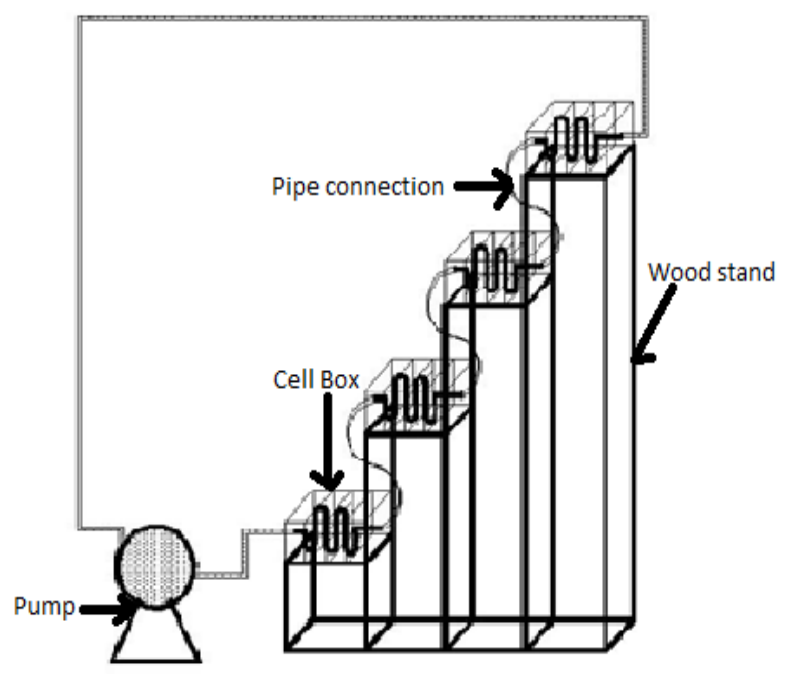

Fig. 1: Advanced setup with baffle agitation system.

\subsection{Introducing Commercial Electrodes in biofuel cell}

To observe the effectiveness of commercial electrodes, the experiment was run with same connections of electrolyte and surface area for traditional electrodes (pure $\mathrm{Zn} \mathrm{\&} \mathrm{Cu}$ ) and commercial electrodes.

\subsection{Measurement of volt, current, internal resistance of biofuel cell}

A digital multi meter (DT - 830B) was used to measure current (I) and potential (V) and recorded every hour connecting $50 \Omega$ as external circuit. For polarization, current generation was monitored at various external resistances connected for a few minutes and readings were noted after stabilization of voltage. Power (W) was calculated using the equation $\mathrm{P}=\mathrm{IV}$, where $\mathrm{I}$ is in amperes and $\mathrm{V}$ is in $\mathrm{mV}$. Power density (W/ m3) was computed according to Fan and his coauthors [7].

\section{RESULTS AND DISCUSSION}

\subsection{Selection of Bio-electrolyte}

Primarily selected organic-acid-rich biomasses were tomato juice, tamarind juice, and milk whey. Their suitability was studied on the basis of some properties like $\mathrm{pH}$, electric conductivity, economical and easily available.
Table 2: $\mathrm{pH}$ of bio-electrolytes

\begin{tabular}{|c|c|c|c|c|}
\hline $\begin{array}{l}\text { Juice } \\
\text { Source } \\
\text { (Fresh) }\end{array}$ & Whey & $\begin{array}{l}\text { Green } \\
\text { Tomato } \\
\text { (Solanum } \\
\text { lycopersci } \\
\text { um) }\end{array}$ & $\begin{array}{l}\text { Red } \\
\text { Tomato } \\
\text { (Solanum } \\
\text { lycopersci } \\
\text { um) }\end{array}$ & $\begin{array}{l}\text { Tamarind } \\
\text { (Tamarind } \\
\text { us indica) }\end{array}$ \\
\hline $\mathrm{pH}$ & $3.1-3.3$ & 3.6 & 3.9 & 3.0 \\
\hline $\begin{array}{l}\text { Conduct } \\
\text { ivity } \\
(\mu \mathrm{S} \text { or } \\
\Omega-\text { ) }\end{array}$ & 4.6 & 3.6 & 3.2 & 4.77 \\
\hline
\end{tabular}

Tomato and tamarind juice have low $\mathrm{pH} \&$ high electric conductivity (Table-2) but they are not available for around the year, they are seasonal fruits. Moreover, they do not have significant superiority over whey regarding $\mathrm{pH}$, conductivity and cost. Therefore, subsequent study was carried on with whey. The milk whey is the by-product of cheese production. Whey is an acidic, yellow-green liquid which is the residue obtained from the coagulation of milk by rennet or by the lowering of its $\mathrm{pH}$ [8]. This is mainly a waste product from dairy farm. The supply of whey can be available around the year and there is no use of it. As a result, all production of whey is thrown away into the drain. In this study, whey that we used, was collected from Fiza \& Co., Iskon other food industry from Sylhet city.

\subsection{Availability of Bio-Electrolyte (Whey)}

Most of the food industry (mainly Sweets Company) use milk to produce their product and drainage whey as waste. The total amount of whey produced in Sylhet city is approximately 7000L/Day; data were collected but not presented here. Therefore, it could be expected that a huge amount of waste whey could be collected from throughout the country mainly from city.

\subsection{Bio-Electrolyte Preservation}

Bio-Electrolyte solution was affected by microbial attack when no preservative was added. After few days whey was found contaminated with pungent smell with heavy layer on the surface. Subsequently, to preserve the collected whey several steps were taken, such as (1) fresh bio-electrolyte without phenol \&thermal treatment, (2) with antimicrobial reagent (2\% Phenol), (3) with thermal treatment. The physical appearance (change of color, microbial growth) of bio-electrolyte with different preservation techniques was observed to select a suitable one. Comparative study of these three methods showed that fresh bio-electrolyte was affected by microorganism so quickly and thermal treatment could save bio-electrolyte from microbial attack for few days but $2 \%$ phenol was more effective to preserve bio-electrolyte for a long duration. 


\subsection{Effect of initial pH}

Our previous study proved that initial $\mathrm{pH}$ of the electrolyte plays an important role to generate electricity. Therefore, initial $\mathrm{pH}$ and their changes were observed for different preservation techniques. Initially there were a little bit difference of $\mathrm{pH}$ among three types of electrolyte but as the time interval increase the $\mathrm{pH}$ was increased but difference among them was continuously reduced (Fig. 2). At the end of the experiment the $\mathrm{pH}$ of three types of electrolyte was almost same. That means, preservation techniques did not influence the initial $\mathrm{pH}$ as well as they would not be manipulate the current generation.

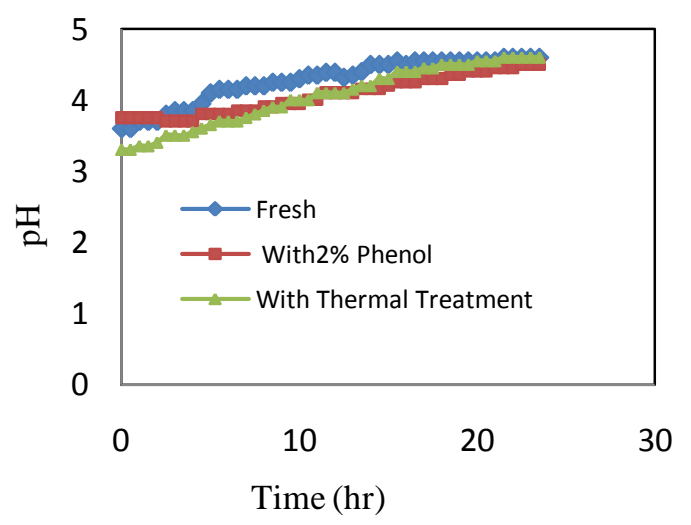

Fig. 2: Change of $\mathrm{pH}$ with electrolyte of three different properties

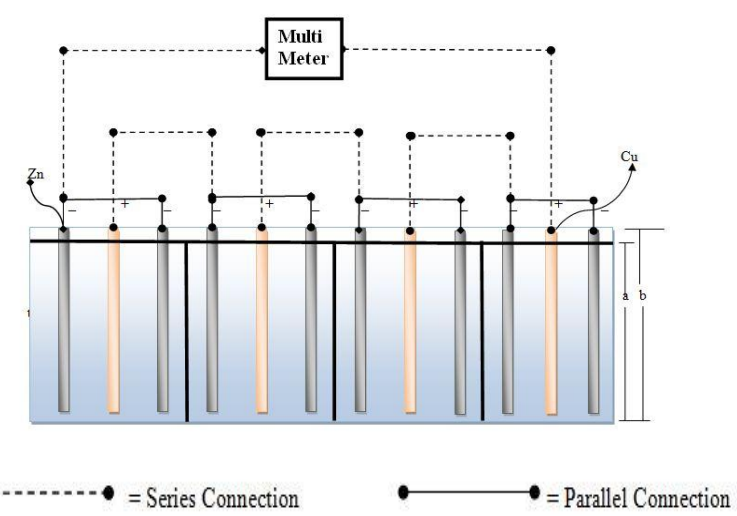

Fig. 3: Arrangement of a bio fuel cell (Anode: cathode ratio 2:1).

\subsection{Effect of surface area of anode on the reduction of polarization}

The power output could be increased by lowering the internal resistance or by lowering the polarization on the electrodes. The polarization can be reduced by increasing the anode surface area (Fig. 4). Therefore, the cells were designed by increasing anode area for 2:1 ratio of anode and cathodes. There were four chambers of each cell-box and each chamber had two anodes and a one cathode plate. The anodes were in parallel connection and cell-boxes were in series connection (Fig. 3). It was observed from Fig.4 that the voltage was remarkably amplified and initial power density was very high (Fig. 5) when the surface area of anode was increased. It might happen due the reduction of resistance with increase of electrode surface area.

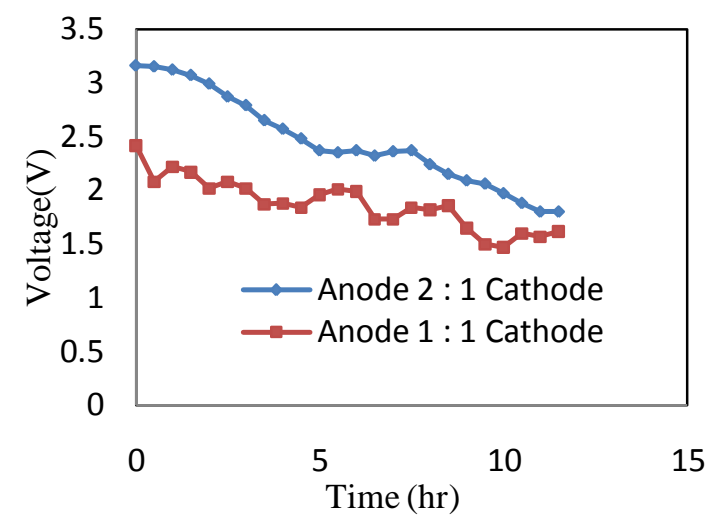

Fig. 4: Change of Voltage with fresh Bio-electrolyte with different anode areas.

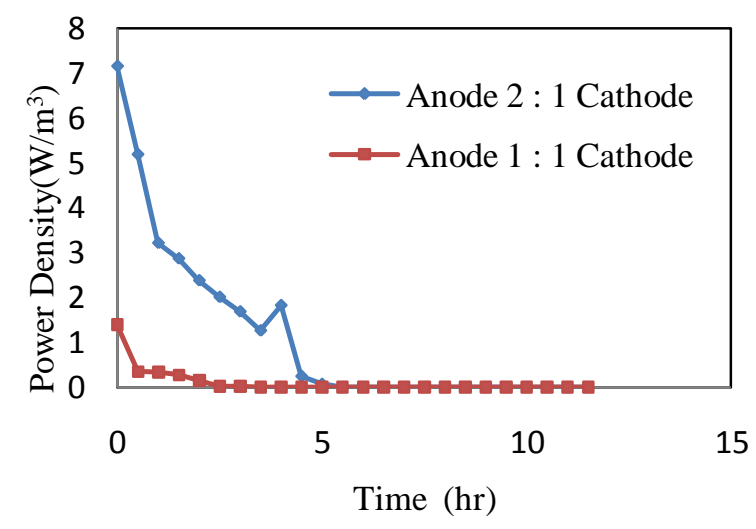

Fig. 5: Change of Power Density with fresh Bioelectrolyte with different anode surface areas.

\subsection{Whey Analysis}

After finishing the experiment with thermal treated electrolyte the suspended solid (SS) decreased and the total dissolves solid (TDS) increased. The $\mathrm{pH}$ of the electrolyte was also increased. Before running the experiment we heated the electrolyte at $70^{\circ} \mathrm{C}$ and cooled it at room temperature. During agitation process the temperature of the electrolyte increasing continuously because the centrifugal pump was not running with fully open discharge. So, into the casing of the centrifugal pump some kinetic energy is converted into the thermal energy. Thus the temperature of the electrolyte was gradually increased. So, it was found that the temperature of the electrolyte was 30 to $45^{\circ} \mathrm{C}$ during operation. As we know that the 
solubility of a solvent is increased by increasing the temperature. During the experiment the solubility of the electrolyte was increased and the total dissolve solid of electrolyte increased from 24.8 to $28.73 \mathrm{~g} / \mathrm{L}$ (Fig. 6).

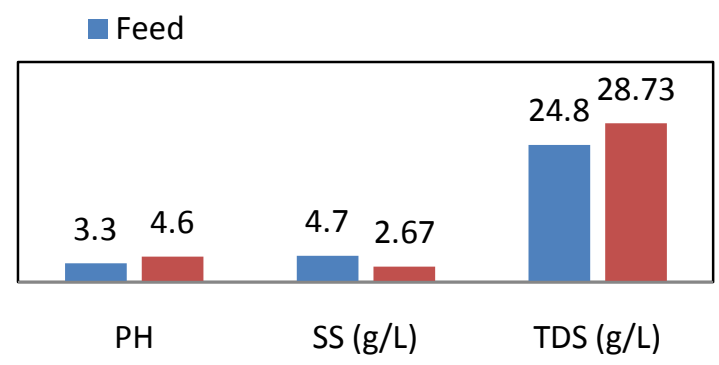

Fig. 6: Comparison study between thermal treated feed electrolyte and exhausted electrolyte

Due to the high amount of suspended solid in electrolyte when the experiment was run each compartment behaved as a settling chamber. As a result, large number of suspended solids deposited at the bottom of the compartment. So, the total suspended solid of electrolyte was decreased from 4.7 to $2.67 \mathrm{~g} / \mathrm{L}$. The $\mathrm{pH}$ of the electrolyte increases from 3.1 to 4.6.That means the acidity of the electrolyte is decreased. The color of the electrolyte was changed from greenish to light green. So it should be concluded that this process have a positive effect on environment. If the fresh electrolyte is harmful for environment then the exhausted electrolyte must be less harmful.

\subsection{Comparison between Experimental and Commercial Electrodes}

We started our experiment with fresh whey without phenol and without thermal treatment. Total volume of the Bio-Electrolyte for each box was 1.25 Liter. Fig. 7 shows the clear difference between the performance of experimental electrodes and commercial electrodes in terms of voltage difference.

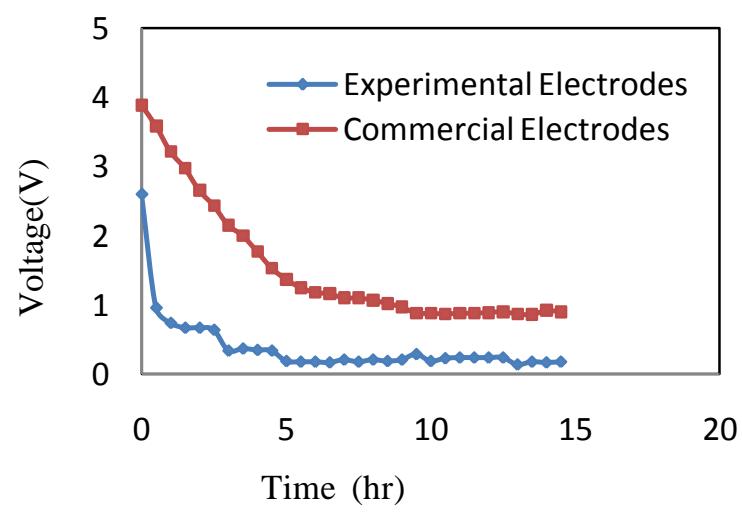

Fig. 7: Change of Voltage for experimental and commercial electrodes for a single box.

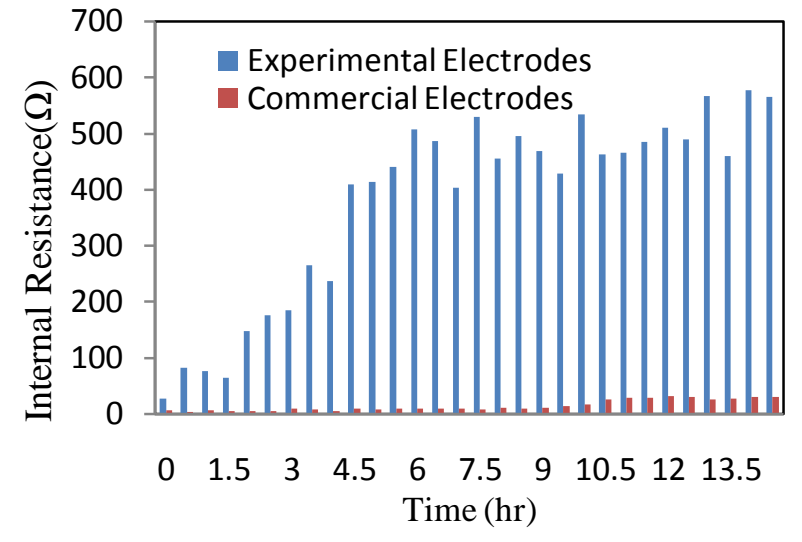

Fig. 8: Variation of internal resistance for experimental and commercial electrodes.

Commercial electrodes were much more effective than experimental electrodes because with same connection and same volume of Bio-electrolyte the commercial electrodes generated much current, voltage and power. The maximum power $\left(\mathrm{P}_{\max }\right)$ obtained for experimental electrodes was $0.12376 \mathrm{~W}$ and maximum voltage, $\mathrm{V}_{\text {max }}$ $=2.6 \mathrm{~V}$ whereas for commercial electrodes the values were $\mathrm{P}_{\max }=0.30264 \mathrm{~W}$ and $\mathrm{V}_{\max }=3.88 \mathrm{~V}$.

The internal resistance rapidly increased and reached to the peak value within 6-8 hrs for experimental electrodes. On the other hand, those values were increased much slowly for commercial electrodes (Fig.8) and maximum value of resistance was only $30 \Omega$. So, commercial electrodes were much more economical and efficient to generate electricity from the biofuel cell.

\section{CONCLUSION}

Among various electrolytes whey were chosen considering the availability and environmental aspects of it. The most significant parameters were agitation effect, flow rate, $\mathrm{pH}$ and surface area of electrode. A small scale electricity generation plant was set up with the facility of agitation. Maximum voltage $13 \mathrm{DCV}$ was obtained, from which a 6 DCV LED bulb was lightened. The electricity found from the cell at an average equal rate for a long time until the $\mathrm{Zn}$ plates get totally corroded. By generating electricity from whey it can relieve the economic problem as well as the environmental problem created by waste of food industry. Electrification with this technology in inaccessible areas usually lead to low investment and less power losses associated with transition and distribution network. This will accelerate the recovery of power crisis and achieve the desired goal. 


\section{ACKNOWLEDGEMENT}

This work was done under full financial support of Shahjalal University of Science \& Technology Research Center.

\section{REFERENCES}

[1] Sieniutycz, S., Thermodynamic aspects of power generation in imperfect fuel cells: part I', International Journal of Ambient Energy, 31(4): 195-202, 2010.

[2] Mench, M. M., Wang, C. and Thynell, S. T., An Introduction to Fuel Cells and Related Trans-port Phenomena', Report of the Pennsylvania State University, University Park, PA, USA, 2009.

[3] Zbikowski, M., Thermodynamic Modeling of Electrochemical Processes in Proton-Exchange Fuel Cell, PhD thesis, Faculty of Chemical and Process Engineering, Warsaw University of Technology, 2004.
[4] Larminie, J. and Dinks, A., Fuel cell systems explained, Wiley: New York, 2000.

[5] Zhao, Y., Ou, C. and Chen, J., A new analytical approach to model and evaluate the performance of a class of irreversible fuel cells'. International Journal of Hydrogen Energy, 33: 4161- 4170, 2008.

[6] Kumaraswamy, P. R. and Datta S., Bangladeshi gas misses India's energy drive? Energy Policy, 34(15): 1971-1973, 2006.

[7] Fan, Y., Hu, H., and Liu, H., Enhanced Coulombic efficiency and power density of air-cathode microbial fuel cells with an improved cell configuration, Journal of Power Sources, 171: 348-354, 2007.

[8] Thivend, P., Use of whey in feeding ruminants with particular reference to pollution problems, 1978.available http://www.fao.org/docrep/004/X6512E/X6512E0 9.htm 